\title{
Can groups be trusted? An experimental study of collective trust
}

\author{
Bill McEvily, Graduate School of Industrial Administration, Carnegie Mellon University \\ Roberto A. Weber, Social and Decision Sciences, Carnegie Mellon University \\ Cristina Bicchieri, Social and Decision Sciences, Carnegie Mellon University \\ Violet Ho, Graduate School of Industrial Administration, Carnegie Mellon University
}

July $10,2002^{*}$

\begin{abstract}
Several previous studies measure the extent to which individuals trust other individuals and argue that individual trust is an important element of interaction in organizations and markets. However, a related topic is the extent to which it is possible for individuals to trust groups as separate entities. This concept, referred to as collective trust, has been previously discussed but not carefully demonstrated. We conduct experiments that specifically address the question of whether it is possible for individuals to exhibit trust for a group, beyond the trust they exhibit for individual members of that group. Using the trust (or investment) game, our results show that individuals exhibit collective trust: They transfer perceptions of trustworthiness to individuals based on previous experiences with members of that individual's group, even with a very minimal form of group membership.
\end{abstract}

JEL Classification: C92 Keywords: trust, group identity

\footnotetext{
* Corresponding author: Bill McEvily, Graduate School of Industrial Administration, Carnegie Mellon University, Pittsburgh, PA 15213, Phone: 412-268-3224, Fax: 412-268-7064, e-mail: bmcevily@andrew.cmu.edu. We are grateful to Robyn Dawes, Mark Fischman, and Laurie Weingart for helpful comments and suggestions.
} 


\section{Introduction}

Trust is the topic of a considerable amount of recent research in the social sciences. This trend is particularly noteworthy in the economics, organizational, and strategy literatures, where trust is considered extremely important for many kinds of interaction. For instance, several economists argue that trust is an essential "lubricant," without which even the simplest forms of economic exchange can not occur (Arrow, 1974). ${ }^{1}$ Trust increases the efficiency of exchange by reducing the expectation of opportunistic behavior and consequently lowering associated transaction costs (Bromiley and Cummings, 1995; John, 1984). Strategy researchers suggest that trust is a strategic resource that has the potential to provide a source of sustained competitive advantage (Barney and Hansen, 1995), while other organizational researchers conceptualize trust as a governance form that provides a framework to guide and direct the organization and coordination of economic activity (Bradach \& Eccles, 1989; Powell, 1990).

Incorporating the concept of trust into economic, strategic, and organizational theories clearly holds the potential of producing far-reaching implications for our understanding of exchange, competition, and behavior in economic and organizational settings. By focusing on the motives and intentions of economic actors, this line of research promises to explicitly investigate and sharpen the core assumptions upon which theory is based. At the same time, however, integrating the concept of trust into existing theory poses a number of challenges. Chief among these is the question of how to extend - or whether it is reasonable to extend - an individual-level construct such as trust between individual actors to more aggregate levels of analysis.

To a large extent placing trust in individuals and placing trust in collective entities (e.g., groups, organizations, industries, institutions) are used interchangeably in the literature and 
without specific consideration for whether differences in the object of trust are meaningful or appropriate. For example, transaction costs economics proposes that "human agents are given to opportunism" (Williamson, 1985; 64), but that firms must safeguard their transactions against the threat of such untrustworthy behavior. As a result there is ambiguity about the object of trust that is most relevant to minimizing transaction costs of exchange - the individual agent or the partner organization. This raises several questions. Does trust exist at different levels of analysis (individual versus collective)? If so, is trust across levels related and does trust at one level influence trust at another? For instance, if I trust the individual agent with whom I deal, then am I necessarily more inclined to trust that person's organization? Or is it even possible to trust a collective entity, independent of the trust I have for the individuals that comprise it? And, perhaps most importantly, does trust at different levels of analysis affect economic behaviors in different ways?

Surprisingly, these fundamental questions have received relatively little research attention despite the widespread application of trust to economic and organizational relationships involving collective entities. A notable exception is a study by Zaheer, McEvily \& Perrone (1998) that explores, using surveys responses of participants in real buyer-supplier interfirm exchanges, the relationship between trust in a specific individual dealt with and trust in that individual's organization. Zaheer, et al., (1998) find that individual and collective trust are related, but distinct; economic agents discriminate between individual and collective trust, but also view trust at different levels of analysis as strongly related. Their study does not, however, specifically address how trust at one level of analysis translates into and influences trust at another level. Moreover, since the study relies on survey responses and not on a behavioral

\footnotetext{
${ }^{1}$ For similar arguments in sociology see Granovetter (1985) and Macauley (1963).
} 
measure of trust, there exists the possibility that individual's perception of collective trust is mistaken and that they only actually exhibit individual trust when making decisions.

The purpose of this paper is to address this important question by examining the relationship between individual and collective trust and their relationship to economic behavior. We propose that trust can be meaningfully applied to economic transactions involving both individual and collective entities, and that trust at these two levels are related. Economic actors form perceptions about the trustworthiness of collective entities based on exchanges conducted with individual members of the collectivity. This collective trust then becomes transferable to other individuals within the collectivity and serves as a proxy for individual trust where detailed knowledge of individual members of the collectivity is limited or absent (McEvily, Perrone \& Zaheer, forthcoming; Stewart, forthcoming). Trust in the collective entity is used as a heuristic for individual trust and is extended to transactions with other members of the collectivity, even those that are unknown and about which there is little or no information on which to determine trustworthiness. In this way, membership in a collectivity or group can be taken to signal trustworthiness (Kramer, Brewer \& Hanna, 1996), without each member having to exhibit his or her trustworthiness directly to all other parties in an economic exchange. The main question we address is simple: Is an individual's perception of a counterpart's trustworthiness affected by the counterpart's membership in a group and by the past actions of others in that group, even in a situation where membership in the group should not convey any meaningful information about trustworthiness?

To explore this question we conducted a laboratory experiment where the outcomes of economic exchanges were influenced by the degree to which subjects' trusted an exchange partners and the extent to which those exchange partners actually upheld the trust that was placed 
in them. Our research builds on previous experiments using the "trust" (or "investment") game (e.g., Berg, Dickhaut \& McCabe, 1995). We extend this paradigm by including a treatment in which we embed exchange within the context of minimally defined collective entities. In this treatment, transactions among individual economic actors are no longer isolated events, but rather are linked through the membership of these individuals in collective entities.

\section{Conceptualizing Individual and Collective Trust}

For the purposes of this paper we use the term individual trust to refer to the extent to which one individual trusts the individual counterpart with whom she deals. Individual trust exists between two individuals. The degree to which a sales representative trusts the purchasing manager she deals with is an example of individual trust. In contrast, collective trust represents the extent of trust that an individual places in a collective entity with which she deals or to which a counterpart belongs. Collective trust exists between an individual on the one hand and a collectivity on the other. A sales representative's trust for the buyer organization that she transacts with is an example of collective trust. The distinction between individual and collective trust is based on the object of trust. Whereas the source of trust resides in individuals for both, the object of trust differs. Rather than being directed at a specific individual, the referent of collective trust is an aggregate social system comprised of a number of individuals. The placement of trust in a collective entity, rather than a specific individual, is consistent with definitions of trust that emphasize "confidence in or reliance on some quality or attribute of a person or thing" (Oxford English Dictionary, emphasis added). While we acknowledge differences in the object of trust, we do not consider differences in the origin of trust. 
Specifically, collective entities placing trust in (e.g., organizations trusting) individuals or other collective entities is beyond the scope of this paper.

Trust is an inherently complex concept (Corazzini, 1977) that has been studied from a number of different disciplinary perspectives. As a result, a wide variety of definitions exist. Despite the heterogeneity in conceptualizations, there are a number of common elements unifying the many different usages of trust. In particular, there is widespread agreement that trust is the willingness to be vulnerable based on the positive expectation of the intentions or behavior of others (Mayer, Davis \& Schoorman, 1995; Rousseau, Sitkin, Burt \& Camerer, 1998). Moreover, for trust to arise, interdependence and uncertainty are necessary conditions. Interdependence means that the interest of one party cannot be fulfilled without reliance on another party. Uncertainty means that the possibility of experiencing negative outcomes by relying on another party requires taking a "leap of faith" (Lewis \& Weigert, 1985). If another's intentions could be ascertained with complete certainty, trust would not be needed. Accordingly, trust is the choice to make oneself vulnerable under the conditions of interdependence and uncertainty.

While the distinction between individual and collective trust is clear, and numerous studies have demonstrated the existence of individual trust, there is no carefully controlled, conclusive study that demonstrates the existence of collective trust. Specifically, it is necessary to conduct a study where a behavioral manifestation of collective trust - separate from any behavioral manifestation of individual trust - is clearly established. Note that it is important to separate collective trust from trust of the individuals that comprise the collective. An individual may claim to trust a certain organization, but may only be referring to the trustworthiness of specific individuals in the organization or of the general population from which the organization 
draws its membership. One may generally believe that people are trustworthy, and therefore most organizations comprised of ordinary people are also trustworthy. Or, one may feel that a group is trustworthy because of familiarity with all of the members of the group and their trustworthiness. We argue that these are not instances of collective trust, since there is no separate attribution of trustworthiness to the organization as an entity itself.

To disentangle individual and collective trust, we designed a laboratory experiment that allowed us to directly explore the possibility that trust may exist for groups, independent of the trust for the individuals in those groups. In the experiments, we created a very basic form of collective using a variant of the well known "minimal group paradigm" (MGP) (Tajfel et al., 1971). The MGP research shows that there is a discontinuity between individual and group behavior: faced with the same choice, people tend to behave differently when confronting another individual or a group, or when they themselves act as group members. The discontinuity is even more striking when the group is created on the basis of an inconsequential criterion, and group membership is anonymous. We thus expected to find a difference in behavior when subjects were faced with "unlabelled" individuals as opposed to members of a designated group. In the absence of previous interactions with a specific member of a group, we were interested in exploring whether an initial experience with an anonymous member of the same group translates into a stereotypical judgment of the whole group, on some chosen dimension.

In particular, we explored the extent to which subjects were likely to exhibit trust for another subject based on experience with a previous member of that subject's group. Specifically, participants in our experiment played the trust game twice. Our focus is on how the actions of the first counterpart affected decisions when playing the game with the second counterpart. We are especially interested in whether membership of the two counterparts in the 
same "minimal group" makes this effect stronger. We find a modest effect, both in magnitude and significance. However, the presence of a positive result, even using the weakest form of group identity in our experiments, lends support to the existence of collective trust. Importantly, this is the first clear, carefully controlled, demonstration that individuals exhibit collective trust.

\section{The Trust Game}

As its name suggests, the trust game creates a situation where one player must decide whether to trust another, and this other must then decide whether to honor or abuse this trust. Specifically, player 1 is given some initial wealth allocation of which she must decide how much to "trust" to player 2. Player 2 can be thought of as an agent of player 1 who has the ability to turn this trusted amount into an even greater sum. Therefore, the amount received by player 2 is some multiple of the amount trusted to player 2 by player 1 . After receiving this amount, player 2 must decide how much, if any, of the total amount received to return to player 1.

This game models several situations in which the attractiveness to one party of a welfareincreasing investment hinges on the trustworthiness of another. For instance, consider a situation where the owner of a small firm has to decide how much training to provide an employee. This training is costly for the owner of the firm, but can yield greater profits for both the employee and the firm, provided the employee remains with the firm after the training. Once the owner decides how much to commit to training and the training actually takes place, the employee then decides how long to remain with the firm. Assuming that the employee can realize greater profit by leaving to go to another firm once the training is received, the problem is exactly the one modeled by the trust game. Player 1 (the owner) decides how much of some allocation to commit to player 2 (the employee), who then decides whether to honor this trust (remain with the 
firm, in which case both employee and owner receive a better payoff than if there had been no training) or abuse this trust (leave the firm immediately after training, yielding the highest payoff to the employee but the lowest to the owner).

The game can also be described formally. In the continuous version of the game, player 1 is given some amount $\mathrm{W}>0$, which she can divide between one amount she keeps for herself and one she trusts to player 2. Label the amount she trusts to player 2 as $\mathrm{x}$, with $0 \leq \mathrm{x} \leq \mathrm{W}$. The amount $\mathrm{x}$ is then multiplied by a constant, $\mathrm{r}>1$, so that the second player receives the greater amount $\mathrm{r} x$. Player 2 must then decide what proportion, $\mathrm{k}$, of $\mathrm{r} \mathrm{x}$ to return to player 1 , keeping the rest, (1-k) r x, for himself. Assuming that player 2 also receives some fixed sum $\mathrm{c}$ (which might be zero), the following are the payoffs for the game:

$$
\begin{array}{ll}
\text { Payoff to player } 1 & =(\mathrm{W}-\mathrm{x})+\mathrm{x} \mathrm{r} \mathrm{k}=\mathrm{W}+(\mathrm{k} \mathrm{r}-1) \mathrm{x} \\
\text { Payoff to player } 2 & =\mathrm{c}+(1-\mathrm{k}) \mathrm{r} \mathrm{x}
\end{array}
$$

Player 2 moves second and the choice of $\mathrm{k}$ does not affect $\mathrm{x}$, which has already been determined. Therefore, as long as player 2 is maximizing his monetary payoff, he will select $\mathrm{k}$ equal to zero and keep the entire amount $\mathrm{r} x$. Knowing this, player 1 should always keep the entire amount $\mathrm{W}$ and set $\mathrm{x}$ equal to zero. Thus, in the unique subgame perfect equilibrium to the game, $\mathrm{x}=\mathrm{k}=0$, Pay $1=\mathrm{W}$, and Pay2 $=\mathrm{c}$.

The game is interesting, however, because trust on the part of player 1 can lead to an outcome that Pareto-dominates this equilibrium. This is true for any outcome in which $\mathrm{x}$ is greater than zero and $\mathrm{k} \mathrm{r}$ is greater than one, meaning that player 1 invests a positive amount and receives more than that amount back from player 2 . 
The trust game has been studied in laboratory experiments. In the first example of such a study, Berg, Dickhaut and McCabe (1995) used the trust game to determine whether or not trusting behavior can be found when social enforcement is not possible. In their experiments subjects played the game in an environment where the usual self-interested motivations assumed by economists to lead to trusting behavior were eliminated. Subjects played the game only once and under complete (double-blind) anonymity. In spite of this anonymity and lack of repetition, only 2 of the 32 subjects in the role of player 1 sent $\$ 0$. On the other hand, 5 subjects sent the entire amount of $\$ 10$. The average amount sent was $\$ 5.16$ and the average amount returned was $\$ 4.66$, indicating that sending money led to slight losses on average for player $1 .^{2}$

Taken together, the experiments by Berg, et al., and others using different variations of the trust game - with varying payoffs and parameters - show some consistent results, even across cultures (e.g., Van Huyck, Battalio, and Walters, 1995; Güth, Ockenfels, and Wendel, 1997; Snijders and Keren 1998; Buchan, Croson and Johnson, 2000). First, the subgame-perfect equilibrium prediction is rarely played. Most subjects in the role of player 1 send a positive amount to player 2. This is true even in the experiments by Berg, et al, in which the design was such that trust enforcement mechanisms were reduced. On the other hand, most subjects who sent money as player 1 did not send the full amount W. A second main finding is that while many subjects in the role of player 2 returned a positive amount to player 1 , the returns tended to be slightly less than the original investment on average. Therefore, while subjects in general exhibited trusting behavior, this trust was often repaid, but usually not sufficiently to prevent it from being costly. Consequently, in our experiments, which use a variation of the trust game, we expect a significant amount of trusting behavior. However, our attention is primarily on whether

\footnotetext{
${ }^{2}$ However, the average return for sending $\$ 5$ and $\$ 10$ was $\$ 7.17$ and $\$ 10.20$, respectively. Berg, et al., argue that the higher returns for these two amounts may reflect social norms concerning behavior towards players who sent
} 
this behavior is increased by the interaction between past experience and shared group identity of counterparts.

One previous study has explored the connection between group boundaries and trust, although with an entirely different focus than ours. Buchan, Croson, and Dawes (2001) used random assignment to divide subjects into two groups (Proposers and Responders) and then used the trust game to measure the extent to which subjects in the first group exhibited trust for subjects in the second group. The treatment variable was the nature of the relationship between Proposers and Responders. In a Direct condition, a Proposer sent money to a Responder who then sent money back to the same Proposer. In a Group condition, Proposer A sent money to Responder A while Proposer B sent money to Responder B, and Responder A then sent money back to Proposer B while Responder B sent money back to Proposer A. In this condition, reciprocity was indirect, but two Proposers and two Responders were mutually linked by their actions. Finally, in a Society condition, Proposer A sent money to Responder B who sent money back to a randomly selected Proposer C. In this condition, reciprocity was indirect and links between Proposers and Responders were much more distant than in the Group condition. The results in all three conditions revealed significant amounts of trust and reciprocation, though both of these decreased as the interaction between Proposers and Responders became less direct. Buchan, et al.'s, experiments demonstrate that trust exists even when it involves indirect reciprocation between members of randomly determined groups, but that this trust (measured by the amount sent by Proposers) is less the more indirect the relationship.

The main point of interest of the work by Buchan et al. for our experiments is that they find that subjects exhibit trusting behavior even when the object of this trust is not directly responsible for reciprocating it. One interpretation of their results is that, even with groups 
determined by an entirely random process, subjects are willing to trust others when someone else in this other's group must reciprocate this trust. In this case the object of trust seems to be the group rather than a specific individual. ${ }^{3}$ While the experiments do not constitute a direct test of collective trust, the results are consistent with the notion that subjects can trust a group rather than an individual.

Our experiments differ from those of Buchan, et al., in that we directly explore collective trust. In particular, we focus on whether a subject's past history of dealing with one member of a group influences that subject's propensity to trust another member of the same group.

\section{Experimental Design}

Our experiment tests whether subjects assigned minimal group labels use these labels to draw inferences about the trustworthiness of other individuals. In our experiment, subjects play the trust game twice against two subjects randomly selected from the population of other participants. Our treatment variable is the relationship between these two other subjects. In the Control condition, they are simply referred to as two other subjects of the opposite role (Player 1 or Player 2), which was randomly determined at the beginning of the experiment. In the Group condition, these two other subjects are members of the same "minimal group" that was determined by responses to an unrelated question. We are particularly interested in how subjects respond to the outcome of the first game, when playing the second time. Our hypothesis is that subjects in the Group condition will be more influenced by what their first counterpart did than those in the Control. Therefore, our experiment is primarily intended to test whether perceptions

\footnotetext{
${ }^{3}$ A plausible interpretation of this "group effect" is that trusting behavior is normative, in the sense that it is part of a script that is primed by the experimental situation. If trusting behavior is primed, it will be rather insensitive to the object of trust, be it a specific person of a group member.
} 
of trustworthiness are transferred more readily across individuals who are in the same group than across individuals with no such group label.

Subjects in our experiment played two rounds of the following discrete version of the trust game:

- Player 1 was given an allocation of $\$ 4$ at the beginning of the game.

- Player 1 then chose an amount to send to Player 2. This amount was $\$ 0, \$ 2$, or $\$ 4$.

- Player 2 received an amount equal to 4 times the amount sent by Player 1.

- Player 2 then decided whether to return to Player 1 either $\$ 0$ or half of the amount received.

Note that this is the same as the trust game discussed in the previous section, with $\mathrm{W}=\$ 4, \mathrm{x} \in$ $\{\$ 0, \$ 2, \$ 4\}, \mathrm{r}=4, \mathrm{c}=\$ 0$, and $\mathrm{k} \in\{0, \ldots\}$. Therefore, the payoffs to Player 1 and Player 2 , respectively, were:

$$
\begin{array}{ll}
\text { Payoff to player } 1 & =4+(4 \mathrm{k}-1) \mathrm{x} \\
\text { Payoff to player } 2 & =(1-\mathrm{k}) 4 \mathrm{x} .
\end{array}
$$

As in other versions of the trust game, the unique subgame-perfect equilibrium is for Player 1 to send $\$ 0$ and for Player 2 to return $\$ 0$ for any amount received, leaving Player 1 with $\$ 4$ and Player 2 with $\$ 0$. However, this equilibrium outcome is Pareto-dominated by the outcome in which Player 1 sends $\$ 4$ and Player 2 returns half, leaving both players with $\$ 8$.

Each of the sessions in our experiment consisted of 10-20 subjects recruited from a distribution list of students at Carnegie Mellon and the University of Pittsburgh. At the beginning of the session, subjects were divided into two groups (how this was done is explained below). Each subject then played the game twice, in the same role, with two randomly selected 
subjects from the other group. Subjects did not know the identity of the other subjects they were playing the game with.

In each play of the game, actions were made and recorded using a Choice Sheet. At the beginning of the game, Player 1 circled on this sheet how much he or she wanted to send to Player 2. The sheet was then collected, the choice recorded, and the sheet was given to a Player 2. This Player 2 then circled his or her choice of how much to send back to Player $1 .^{4}$ The sheets were then collected, the choices recorded, and the sheet was given back to Player 1 who could observe the outcome of the game. Players also had Record Sheets on which they recorded what happened in each of the two games.

The difference between the two treatments was in how the groups were determined and in the labels used to refer to the two roles.

- In the Control condition, subjects were randomly assigned participant numbers at the beginning of the experiment. They were then told that odd participant numbers corresponded to the role of Player 1 and that even participant numbers corresponded to the role of Player 2. Subsequently, the two roles were referred to as "Player 1" and "Player 2."

- In the Group condition, subjects were also randomly assigned participant numbers, but these were not used to determine the roles. Instead, subjects were asked to make a guess about the number of days it would rain the following year in San Francisco. A median split of these guesses was then used to divide the subjects into two groups: High Guessers and Low Guessers. High Guessers played the role of Player 1, while Low

\footnotetext{
${ }^{4}$ In the event that Player 1 had sent $\$ 0$, Player 2 did not need to make a choice, but we still required them to circle "no choice" on the sheet so it would not be apparent who had received $\$ 0$ from their failure to circle something on the sheet.
} 
Guessers played the role of Player 2. Subsequently, all reference to the two roles was made using the terms "High Guessers" and "Low Guessers."

Note that this is a very weak group manipulation. In one condition, the roles are simply determined by a guess about something unrelated to the game. There was no other difference between the two treatments. In both treatments, subjects who were in the role of Player 1 were seated on one side of the room while subjects in the role of Player 2 were seated on the other.

We conducted 12 sessions (6 in the Control condition and 6 in the Group condition), using a total of 174 Carnegie Mellon and University of Pittsburgh graduate and undergraduate students (80 in Control and 94 in Group). The sessions were conducted between September 2000 and May 2001.

\section{Results}

Our main hypothesis is that the interaction between experience and experimental treatment affects the amount sent in the second round by Player 1. Specifically, the presence of collective trust implies that subjects in the Group condition will be more influenced by experience than subjects in the Control. Before looking at this, however, we first look at the aggregate data for other patterns of behavior related to the group manipulation.

\section{$\underline{\text { Aggregate Results }}$}

Table 1 presents the total amounts sent by subjects in the role of Player 1 by condition. As the results in the table indicate, the aggregate choices by subjects do not differ greatly by condition. There are slightly more Player 1's who sent $\$ 4$ in the Control condition (60\%) than in the Group condition (48\%), but this difference is not significant. Moreover, almost twice as 
many subjects in the Group condition (32\%) than in the Control condition (18\%) initially sent $\$ 2$. In fact, while about 80 percent of subjects in the role of Player 1 sent some amount of money in the first round, a larger proportion of those sending some money sent $\$ 4$ in the Control condition ( 25 of $32,78 \%$ ) than in the Group condition ( 22 of $37,59 \%)$. This difference in amount sent among those who sent money is significant in a Fisher Exact test $(p=0.08)$. However, this pattern is reversed - but is not significant - when we look at the choices in Round 2. ${ }^{5}$ Note also that in both treatments the frequency of players sending $\$ 0$ increased between Rounds 1 and 2, and that this increase was greater in the Group condition (from 21 to 40 percent) than in the Control condition (from 20 to 28 percent). Overall, among subjects in the role of Player 1, there are slight differences in behavior between the two conditions when looking at the aggregate data - such as the different distributions of amounts sent among those who sent money.

\begin{tabular}{l|cccc} 
Condition & Amount sent & Round 1 & Round 2 & Total \\
\hline Control & $\$ 0$ & $8(20 \%)$ & $11(28 \%)$ & $19(24 \%)$ \\
& $\$ 2$ & $7(18 \%)$ & $6(15 \%)$ & $13(16 \%)$ \\
& $\$ 4$ & $25(63 \%)$ & $23(58 \%)$ & $48(60 \%)$ \\
\hline Group & $\$ 0$ & $10(21 \%)$ & $19(40 \%)$ & $29(31 \%)$ \\
& $\$ 2$ & $15(32 \%)$ & $5(11 \%)$ & $20(21 \%)$ \\
& $\$ 4$ & $22(47 \%)$ & $23(49 \%)$ & $45(48 \%)$ \\
\hline
\end{tabular}

Table 1. Frequencies of amounts sent by player 1

\footnotetext{
${ }^{5}$ The change is brought about by an increase in the Group condition of the proportion of those sending money that send $\$ 4$. In the Control condition the proportion of those sending money that send $\$ 4$ remains roughly the same.
} 
Table 2 reports the behavior of subjects in the role of Player 2 by role and round. Each entry in the table gives - for each possible amount sent - what proportion of Player 2's returned one-half of the amount received, resulting in an improvement for Player 1 over the initial allocation. The remaining subjects all returned $\$ 0$, resulting in a loss for Player 1 . Cases where Player 2 received $\$ 0$ meant there was no subsequent choice and are therefore not included in the table.

\begin{tabular}{l|cccc} 
Condition & Amount sent & Round 1 & Round 2 & Total \\
\hline Control & $\$ 2$ & $4 / 7(57 \%)$ & $1 / 6(17 \%)$ & $5 / 13(38 \%)$ \\
& $\$ 4$ & $13 / 25(52 \%)$ & $12 / 23(52 \%)$ & $25 / 48(52 \%)$ \\
& Total & $17 / 32(53 \%)$ & $13 / 29(45 \%)$ & $30 / 61(49 \%)$ \\
\hline Group & $\$ 2$ & $3 / 15(20 \%)$ & $3 / 5(60 \%)$ & $6 / 20(30 \%)$ \\
& $\$ 4$ & $11 / 22(50 \%)$ & $12 / 23(52 \%)$ & $23 / 45(51 \%)$ \\
& Total & $14 / 37(38 \%)$ & $15 / 28(54 \%)$ & $29 / 65(45 \%)$ \\
\hline
\end{tabular}

Table 2. Percentage of player 2's returning half by offer

Again, when we look at the aggregate data we see small differences between the two treatments. Note first that in Round 1, the number of subjects who returned half is greater in the Control (53 percent) than in the Group condition (38\%), but this difference is not significant. This difference is largest for subjects who were sent \$2. In the Control condition, 4 of 7 (57\%) such subjects returned one-half; in the Group condition, only 3 of 15 (20\%) such subjects did so. This difference, however, is not significant in a Fisher Exact test $(\mathrm{p}=0.11)$. When pooling across rounds and amounts sent, we see that Player 2's in the Control condition were only very slightly more likely to return half (49 percent) than those in the Group condition (45 percent). 


\begin{tabular}{cccccc}
$\begin{array}{c}\text { Sent in } \\
\text { Round } 1\end{array}$ & $\begin{array}{c}\text { Returned in } \\
\text { Round } 1\end{array}$ & $\begin{array}{c}\text { Trust honored or } \\
\text { abused }\end{array}$ & $\begin{array}{c}\text { Sent in } \\
\text { Round } 2\end{array}$ & Control & Group \\
\hline$\$ 0$ & N/A & No information & $\$ 0$ & $5(13 \%)$ & $7(15 \%)$ \\
$\$ 0$ & N/A & No information & $\$ 2$ & $3(8 \%)$ & $1(2 \%)$ \\
$\$ 0$ & N/A & No information & $\$ 4$ & $0(0 \%)$ & $2(4 \%)$ \\
$\$ 2$ & $\$ 0 / \$ 8$ & Trust abused & $\$ 0$ & $3(8 \%)$ & $8(17 \%)$ \\
$\$ 2$ & $\$ 0 / \$ 8$ & Trust abused & $\$ 2$ & $0(0 \%)$ & $2(4 \%)$ \\
$\$ 2$ & $\$ 0 / \$ 8$ & Trust abused & $\$ 4$ & $0(0 \%)$ & $2(4 \%)$ \\
$\$ 2$ & $\$ 4 / \$ 8$ & Trust honored & $\$ 0$ & $0(0 \%)$ & $0(0 \%)$ \\
$\$ 2$ & $\$ 4 / \$ 8$ & Trust honored & $\$ 2$ & $1(3 \%)$ & $0(0 \%)$ \\
$\$ 2$ & $\$ 4 / \$ 8$ & Trust honored & $\$ 4$ & $3(8 \%)$ & $3(6 \%)$ \\
$\$ 4$ & $\$ 0 / \$ 16$ & Trust abused & $\$ 0$ & $3(8 \%)$ & $4(9 \%)$ \\
$\$ 4$ & $\$ 0 / \$ 16$ & Trust abused & $\$ 2$ & $0(0 \%)$ & $2(4 \%)$ \\
$\$ 4$ & $\$ 0 / \$ 16$ & Trust abused & $\$ 4$ & $9(23 \%)$ & $5(11 \%)$ \\
$\$ 4$ & $\$ 8 / \$ 16$ & Trust honored & $\$ 0$ & $0(0 \%)$ & $0(0 \%)$ \\
$\$ 4$ & $\$ 8 / \$ 16$ & Trust honored & $\$ 2$ & $2(5 \%)$ & $0(0 \%)$ \\
$\$ 4$ & $\$ 8 / \$ 16$ & Trust honored & $\$ 4$ & $11(28 \%)$ & $11(23 \%)$ \\
\hline Total & & & & 40 & 40 \\
\hline & & & & $\$ 10 \%)$
\end{tabular}

Table 3. Choices in Round 2 by Player 1 contingent on outcomes in Round 1

\section{$\underline{\text { Collective Trust Results }}$}

When a subject in the role of Player 1 sends either $\$ 2$ or $\$ 4$ to a Player 2 , the outcome is one of two possibilities: either half the multiplied amount is returned or nothing is returned. In one case, Player 1 is better off - relative to the initial allocation - for having sent an amount greater than $\$ 0$, and in the other Player 1 is worse off. Therefore, we can think of these as situations where initial trust in Round 1 is either "honored" or "abused." The main focus of this paper is to explore what happens in Round 2 when trust is either honored or abused in Round 1 
and, in particular, whether subjects in the Group condition are more affected by these events than those in the Control sessions.

The results in Tables 1 and 2 do not allow us to test this hypothesis because the results are presented at an aggregate level across rounds. Table 3 allows us to explore this hypothesis.

Table 3 presents, for possible outcomes of Round 1, the subsequent Round 2 choices of subjects in the role of Player 1 in each condition. The first two columns in the table present the possible outcomes in the first round. The next column classifies these outcomes into three possible categories from Player 1's point of view: no information (if $\$ 0$ was sent and no action of Player 2 was observed), trust abused (if either $\$ 2$ or $\$ 4$ was sent and $\$ 0$ was returned), and trust honored (if either $\$ 2$ or $\$ 4$ was sent and one-half the multiplied amount was returned). The fourth column presents the possible amounts sent in Round 2 by a Player 1, and the last two columns give the number of subjects in each condition who sent that amount after observing the outcome described in the first three columns.

The results in the table reveal greater sensitivity to prior outcomes in the Group condition than in the Control condition. For instance, of those subjects in the role of Player 1 who sent $\$ 4$ in Round 1 and received back \$0, 9 of 12 subjects ( 75 percent) in the Control condition again sent $\$ 4$. In the Group treatment, however, only 5 of 11 such subjects (45 percent) again sent $\$ 4$. Similarly, of the subjects who sent $\$ 4$ in Round 1 and received $\$ 8$ back, all of the 11 subjects in the Group condition again sent $\$ 4$, but a smaller fraction ( 9 of $11 ; 85$ percent) did so in the Control Group. However, neither of these differences is significant in a Fisher Exact test. Still, these results suggest a subtle greater sensitivity to first round results on the part of subjects in the Group condition and lend support to our hypothesis that experience in Round 1 is more likely to influence behavior in Round 2 in the Group condition than in the Control. 
A direct test of our hypothesis involves looking at how subjects in the role of Player 1 react when their initial trust is either abused or honored. To demonstrate the existence of collective trust, we need to show that subjects in the Group condition whose trust is abused (honored) in Round 1 are likely to send less (more) in Round 2 than subjects in the Control condition whose trust is abused (honored). Table 4 presents the relevant results. Specifically, the Round 2 choices of subjects in the role of Player 1 are given, by condition and outcome in Round 1. Using Table 4, we can see whether behavior in the two conditions differs in the way we predicted, and in a way consistent with subjects displaying collective trust even with the minimal form of groups created in our experiments.

\section{Trust honored in Round 1}

\begin{tabular}{c|ccc}
$\begin{array}{c}\text { Amount sent in } \\
\text { Round } 2\end{array}$ & Control & Group & Total \\
\hline$\$ 0$ & $0(0 \%)$ & $0(0 \%)$ & 0 \\
$\$ 2$ & $3(18 \%)$ & $0(0 \%)$ & 3 \\
$\$ 4$ & $14(82 \%)$ & $14(100 \%)$ & 28 \\
\hline Total & 17 & 14 & 31 \\
\hline
\end{tabular}

\section{Trust abused in Round 1}

\begin{tabular}{c|ccc}
$\begin{array}{c}\text { Amount sent in } \\
\text { Round 2 }\end{array}$ & Control & Group & Total \\
\hline$\$ 0$ & $6(40 \%)$ & $12(52 \%)$ & 18 \\
$\$ 2$ & $0(0 \%)$ & $4(17 \%)$ & 4 \\
$\$ 4$ & $9(60 \%)$ & $7(30 \%)$ & 16 \\
\hline Total & 15 & 23 & 38 \\
\hline
\end{tabular}

Table 4. Choices of Player 1 in Round 2 by Round 1 outcomes and condition 
As the top part of Table 4 indicates, when trust is honored, almost every subject subsequently sends $\$ 4$. In the Group condition, all 14 subjects whose trust was honored subsequently sent $\$ 4$, while in the Control 14 of 17 subjects did so, whereas the other 3 only sent \$2. While the direction of this difference - that subjects in the Group condition whose trust is honored are slightly more likely to send $\$ 4$ in the next round - is consistent with our hypothesis, deviations by three subjects do not produce a significant difference. Nevertheless, though weak, this result does constitute direct support for our hypothesis.

Additional, and more compelling, direct support for our hypothesis can be found in the bottom part of Table 4. Here, we explore the behavior of subjects in the role of Player 1 who had their trust abused in the first round (they sent some amount of money and received $\$ 0$ in return). There is a clear difference in the pattern of choices between the two conditions. In the Control, a majority of subjects ( 60 percent) whose trust was abused still sent $\$ 4$ in the next round. In the Group condition, however, only 30 percent of such subjects did so, and a majority of subjects sent $\$ 0$. The difference between the distributions of actions in the two conditions is significant at the $p<0.1$ level in a chi-square test $\left(\chi^{2}(2)=4.78\right)$. Therefore, we see a significant amount of behavior consistent with our hypothesis of collective trust: subjects in the Group condition whose trust is abused in round 1 were significantly more likely to react negatively in round 2 than those in the Control. ${ }^{6}$

\footnotetext{
${ }^{6}$ We can also use Goodman's (1964) test of 2x2x2 contingency tables to look for our hypothesized relationship between amount send in round 2 , history, and condition. Looking only at decisions to send $\$ 4$ versus a smaller amount in the second round (which is natural given the near 50-50 split of first-round choices using such categories), we find that we can reject the null hypothesis at. This is even though we change one value of 0 to 1 in order to perform this test, making the test more conservative.
} 
Dependent variable:

(1)

(2)

(3)

Amount sent in Round 2

\begin{tabular}{|c|c|c|c|}
\hline Dispositional trust & $\begin{array}{c}0.684^{*} \\
(0.364)\end{array}$ & $\begin{array}{c}0.112 \\
(0.370)\end{array}$ & $\begin{array}{c}0.157 \\
(0.366)\end{array}$ \\
\hline Trust abused (Rd. 1) & & $\begin{array}{c}-1.848^{* * *} \\
(0.371)\end{array}$ & $\begin{array}{c}-1.208^{* *} \\
(0.530)\end{array}$ \\
\hline Group condition & & $\begin{array}{l}-0.283 \\
(0.365)\end{array}$ & $\begin{array}{c}0.376 \\
(0.534)\end{array}$ \\
\hline Trust abused x Group & & & $\begin{array}{l}-1.211^{*} \\
(0.724)\end{array}$ \\
\hline Constant & $\begin{array}{c}0.662 \\
(0.930)\end{array}$ & $\begin{array}{c}3.640^{* * *} \\
(1.033)\end{array}$ & $\begin{array}{l}3.224^{* * *} \\
(1.049)\end{array}$ \\
\hline Obs. & 87 & 69 & 69 \\
\hline R-squared & 0.040 & 0.307 & 0.336 \\
\hline Adjusted R-Squared & 0.029 & 0.275 & 0.294 \\
\hline
\end{tabular}

Table 5. Regression of Amount Sent in Round 2

We can also explore our hypothesis using regression analysis to determine the effect of first-round experience on behavior in the second round. Specifically, we conducted regressions of the amount sent in round 2 on several variables, including an interaction between whether or not trust was abused in Round 1 and the condition. The results of these regressions are reported in Table 5. The variable "Dispositional trust" is a scale of general disposition to trust constructed from seven survey items drawn from Rotter's (1967) Interpersonal Trust Scale. The scale was administered at the end of the experiment. The other predictors in the regression 
model are binary variables indicating whether trust was abused in round 1 , whether the subject was in the Group condition, and the interaction between the two. As the results indicate, if trust was abused, subjects sent significantly less than if it was not. However, the negative effect of trust being abused on amount sent in the subsequent round is even stronger for subjects in the Group condition (roughly twice as big). The statistical significance of the interaction term ( $\mathrm{p}<$ 0.1 ) is greater than that reported in the table if we use a one-sided test (making it $p<0.05$ ), which is appropriate given our initial hypothesis.

\section{Conclusion}

The above analysis reveals support for our hypothesis. Subjects in the Group condition show a greater reaction to previous experience, particularly when this experience is negative. However, the overall effect is not large. This is probably due to several features of our research design. First, even though we used 174 subjects in the experiments, the analysis focuses on only those subjects in the role of Player 1, reducing our sample size by one-half. The sample size is further reduced since we are interested in those subjects who had either a positive or negative experience in the first round, eliminating those who sent $\$ 0$ in the first round. While using deception would have allowed us to collect much more data, we felt that it was important to rely on a situation where subjects were actually matched with two other people in the room and this was transparent.

A second reason for not observing a larger effect has to do with our group manipulation. Our overall argument is that people assign trustworthiness to individuals who are members of particular groups on the sole basis of their group membership, and independent of what they may be able to infer about their trustworthiness from interactions with similar individuals who are not 
group members. In the real world, this is usually due to repeated experience with long-standing groups and organizations that strongly influence their members' lives. In such circumstances, it is reasonable to expect uniformity in behavior by group members. In our experiments, however, the "organization" was simply a group that was randomly determined at the beginning of the experiment by a median split on an irrelevant guess. Therefore, it is striking that we observed any effect with such a slight group identity manipulation and we would expect an even larger effect in situations where the group or organizational identity is stronger.

The results are even more compelling when one considers that our group identity manipulation also likely created an "out-group" bias, which would clearly work against our hypothesis. Individuals tend to view out-groups as less cooperative, honest, and trustworthy and tend to expect less positive behavior from out-group members (Brewer, 1979). Consequently, subjects interacting with counterparts categorized as members of an out-group would be biased toward viewing their counterparts as untrustworthy. Therefore, we expect that having subjects in the Group condition interact with two members of the same group - without it being a counterpart to their own group - might produce more striking results.

These limitations notwithstanding, we believe that this study makes a number of important contributions to research on trust in the economics, strategy, and organizational literatures. Most importantly, the results of our experiment reinforce, and validate in a more carefully controlled setting, the finding by Zaheer et al. (1998) that individual and collective trust are related but distinct. This suggests not only that it is meaningful to conceptualize the placement of trust in a collective entity, but also that collective trust may influence economic activity over and above individual trust. Consequently, it is important to carefully consider which level of analysis is most relevant when theorizing about the role of trust in the 
organization and coordination of economic activity. Further, recognizing that collective trust has a basis in group identification (Kramer, Brewer \& Hanna 1996) is essential.

We also go beyond earlier research on collective trust by highlighting trust transfer as an underlying causal mechanism that links individual and collective trust. The evidence reported here is consistent with the idea that individuals use membership in a collectivity as a heuristic for determining the trustworthiness of members that they have no prior knowledge of or experience with. This finding is striking because it suggests that the effects of an initial experience with a given representative of a collectivity extend beyond that relationship to interactions with other members of the collectivity. New relationships and interactions with previously unknown members of a collectivity do not start from a clean slate, but are construed through the lens of shared group identity with those with whom one has prior experience.

This study also makes a valuable empirical contribution by extending the trust game research paradigm. By embedding exchange relationships within the context of collective entities we are able to broaden the application of the trust game to a wider and more diverse set of phenomena that are more closely related to actual economic organizations and activities (cf. Buchan, Crosona and Dawes, 2001). Future research can draw on the research design developed here to address other questions involving trust in collective entities.

While this study advances our understanding of the relationship between individual and collective trust, it also raises a number of important questions for future research. In particular, understanding the conditions that accelerate, alter, or prevent the process through which trust transfers between individuals and collectivities represents a fruitful area of inquiry. For instance, in an organizational context, do certain structures, process, or incentives fundamentally alter the degree to which individuals rely on group identity as a heuristic for formulating initial trust 
impressions? A related and equally important question would be ascertaining the conditions under which group identity represents a useful and efficient heuristic versus an erroneous and costly bias. To the extent that these different circumstances can be identified, we would also want to gain insight into whether group identity as a basis for trust can be actively managed, produced, or discouraged.

In sum, this research supports the idea that collective trust is related to, but distinct from, individual trust. The findings are consistent with the view that economic actors develop perceptions about the trustworthiness of collective entities based on exchanges conducted with individual members of the collectivity. This collective trust then serves as a heuristic for individual trust where prior history or knowledge of individual members of the collectivity is limited or absent.

\section{References:}

Arrow, K. 1974. The Limits of Organization. New York: Norton.

Barney, J.B. and M.H. Hansen. 1995. "Trustworthiness as a source of competitive advantage," Strategic Management Journal, 15(special issue): 175-90.

Berg, J., J. Dickhaut and K. McCabe. 1995. “Trust, reciprocity, and social history." Games and Economic Behavior 10: 122-142.

Bradach, J.L. and R.G. Eccles. 1989. "Price, authority, and trust: From ideal types to plural forms," Annual Review of Sociology, 15: 97-118.

Brewer, M.B. 1979. "In-group bias in the minimal intergroup situation: A cognitive-motivational analysis." Psychological Bulletin, 86: 307-324.

Bromiley, P. and L.L. Cummings. 1995. "Transaction costs in organizations with trust," in R. Bies, B. Sheppard, and R. Lewicki (Eds.), Research on Negotiation in Organizations, Greenwich, CT: JAI Press. 
Buchan, N, R. Croson and E. Johnson. 2002. "Trust and reciprocity: An international experiment." Unpublished manuscript.

Buchan, N, R. Croson and R. Dawes. 2001. "Direct and indirect trust and reciprocity." Unpublished manuscript.

Corazzini, R. 1977. "Trust as a complex multi-dimensional construct," Psychological Reports, 40: $75-80$.

Granovetter, M. 1985. "Economic action and social structure: The problem of embeddedness," American Journal of Sociology, 91(3): 481-510.

Güth, W., P. Ockenfels and M. Wendel. 1997. "Cooperation based on trust: An experimental investigation.” Journal of Economic Psychology, 18: 15-43.

Hoffman, E., K. McCabe, K. Shachat and V. Smith. 1994. "Preferences, property rights, and anonymity in bargaining games." Games and Economic Behavior 7: 346-380.

John, G. 1984. "An empirical investigation of some antecedents of opportunism in a marketing channel," Journal of Marketing Research, 21: 278-89.

Kramer, R.M., M.B. Brewer, and B.A. Hanna. 1996. "Collective trust and collective action: The decision to trust as a social decision," in R.M. Kramer and T.R. Tyler (Eds.) Trust in Organizations: Frontiers of Theory and Research, Thousand Oaks, CA: Sage.

Lewis, J.D. and A.J. Weigert. 1985. “Trust as Social Reality,” Social Forces, 63(4): 967-985.

Macauley, S. 1963. "Non-contractual relations in business," American Sociological Review," 28: 55-67.

Mayer, R.C., J.H. Davis, and F.D. Schoorman. 1995. "An integrative model of organizational trust," Academy of Management Review, 20: 709-734.

McEvily, B., V. Perrone, and A. Zaheer. (forthcoming). "Trust as an organizing principle," Organization Science.

McKelvey, R. D. and T. R. Palfrey. 1992. "An experimental study of the centipede game," Econometrica, 60(4): 803-836.

Powell, W.W. 1990. "Neither market nor hierarchy: Network forms of organization," in L.L. Cummings and B. Staw (Eds.) Research in Organizational Behavior, 12: 295-336, Greenwich: JAI Press.

Rotter, J.B. 1967. "A new scale for the measurement of interpersonal trust," Journal of Personality, 35: 651-665. 
Rousseau, D.m., S.B. Sitkin, R.S. Burt, and C. Camerer. 1998. "Not so different after all: A cross-discipline view of trust," Academy of Management Review, 23: 292-404.

Snijders, C. and G. Keren. 1998. "Determinants of trust" in D. V. Budescu, I. Erev and R. Zwick (Eds.), Games and Human Behavior: Essays in Honor of Amnon Rapoport. New Jersey: Lawrence Erlbaum Associates.

Stewart, K.J. (forthcoming). "Trust transfer on the world wide web," Organization Science.

Tajfel, H., M. Billig, R.P. Bundy and C. Flament. 1971. "Social categorization and intergroup behavior.” Journal of Experimental Social Psychology 1:149-77.

Van Huyck, J. B., R. C. Battalio and M. F. Walters. 1995. "Commitment versus discretion in the peasant-dictator game." Games and Economic Behavior 10: 143-170.

Williamson, O.E. 1985. The Economic Institutions of Capitalism, New York: The Free Press.

Zaheer, A., B. McEvily, and V. Perrone. 1998. "Does trust matter? Exploring the effects of interorganizational and interpersonal trust on performance," Organization Science, 9(2): 141-159. 